\title{
PSO Research on Cutting Parameters in AWJM Process for Aluminum 6061 Alloy
}

\author{
K.S. Jai Aultrin, M. Dev Anand, R. Rajesh, S. Muthu Sherin
}

\begin{abstract}
In recent years there is a rapid growth in the improvement of complexity, difficult and harder to machine metals and alloys. AWJM is one of the hybrid, nontraditional machining process in machining several hard-to-cut materials these days. Machining parameters play the lead role in determining the machine economics and quality of machining. In this study Particle Swarm Optimization soft computing technique is executed to estimate the optimal process parameters which leads to a least value of machining performance and compared with the machining performance value of experimental data. The approaches suggested in this study involve three components, viz., experimental observation, multi regression modeling and single objective Particle Swarm Optimization. The consequence of Pressure, Abrasive flow rate, Orifice diameter, Focusing nozzle diameter and Stand off distance AWJM process parameters on MRR and SR of Aluminium 6061 alloy which is machined by AWJM was experimentally performed and analyzed. According to Response Surface Methodology design, different experiments were conducted with the combination of input parameters on this alloy. The outcome of this study revealed that the PSO soft computing technique obtains the optimal solution of AWJM process parameters for Aluminium 6061 alloy.
\end{abstract}

Keywords--- Response Surface Methodology, Particle Swarm Optimization, Material Removal Rate, Surface Roughness.

\section{INTRODUCTION AND PAST STUDIES}

AWJC is the recently developed processes. This technique is suitable for machining of brittle materials similar to glass, ceramics and stones as well as for composite materials and ferrous and non-ferrous materials. From the literature review of Adel A. Abdel-Rahman [1] in 2011 an elastic-plastic erosion model was implemented to build up an Abrasive Waterjet (AWJ) model for machining brittle materials. C. Ma, R.T. Deam [2] in 2006 reviewed that kerf geometry have been measured by the use of an optical microscope. With these measurements, an empirical correlation for kerf profile shape under various traverse speed have been developed that fits the kerf shape well. $\mathrm{H}$. Liu, J. Wang, N. Kelson, R. J. Brown [3] in 2004 in their research Computational Fluid Dynamics (CFD) models for ultrahigh velocity waterjets and AWJs are established by the use of Fluent6 flow solver. Hashish [4] used erosion model of Finnie to develop a model to predict combined depth of cut due to cutting and deformation wear for ductile materials

Revised Manuscript Received on July 10, 2019.

K.S. Jai Aultrin, Associate Professor, Department of Mechanical Engineering, Noorul Islam Centre for Higher Education, Kumaracoil, Tamil Nadu, India.

M. Dev Anand*, Professor, Department of Mechanical Engineering, Noorul Islam Centre for Higher Education, Kumaracoil, Tamil Nadu, India. (e-mail: anandpmt@hotmail.com)

R. Rajesh, Associate Professor, Department of Mechanical Engineering, Noorul Islam Centre for Higher Education, Kumaracoil, Tamil Nadu, India.

S. Muthu Sherin, Assistant Professor, Department of Aerospace Engineering, Noorul Islam Centre for Higher Education, Kumaracoil, Tamil Nadu, India. only. Hashish [5] developed an improved erosion model by expanding Finnie's model to include the effects of abrasive particle size and shape (expressed by sphericity and roundness numbers), which was weakness of the earlier model [4]. Hashish used this model to predict depth of cut due to cutting wear, while the prediction of depth of cut due to deformation wear was based on Bitter's model. But, this model neglected the variation in kerf width along the depth of cut. Using the same improved erosion model, Paul et al., [6] developed analytical model of generalized kerf shape for ductile materials considering variation in kerf width along its depth. Same authors [7] also developed a complex mathematical model for total depth of cut for polycrystalline brittle materials accounting for the effects of abrasive particle size and shape, but neglecting variation of kerf width along the depth of cut. Choi and Choi [8] developed an analytical model for AWJM of brittle materials. Expression developed by them to predict volume of work material removed by a single abrasive. Particle is not in terms of process parameters and moreover involves constant of proportionality.

\section{EXPERIMENTAL WORK}

\section{Material}

Aluminium occupies third place among commercially used engineering materials after Iron and Copper. The normal purity of Aluminium from its ore i.e. bauxite ranges from 99.0 to $99.5 \%$. The main impurities are Iron and Silica. The important factor in selecting Aluminium and its alloys are their high strength to weight ratio, their resistance to corrosion by many chemicals, their high thermal and electrical conductivity, non toxicity, reflectivity, and appearance, and their ease of formability and machinability and non magnetic properties. The important uses of Aluminium and its alloys are in container and packaging (cans and foils), in building in other type of constructions, in transportation (aircraft and aero-space applications, buses, automobile, railway, and marine craft), in electrical applications (economical and non-magnetic electrical conductor), in consumer durables (appliances, cooking utensils and furniture), and in portable tools. Nearly all high voltage transmission line is made of Aluminium. Aluminium alloys are available as mill products, which are, as wrought products made in to various shapes by rolling, extrusion, drawing and forging. Aluminium ingots are available for casting as is Aluminium in powder form for powder metallurgy applications. Its density is $2.7 \mathrm{~g} / \mathrm{cm}^{3}$ and its modulus of elasticity $\mathrm{E}=80 \mathrm{GPa}$.

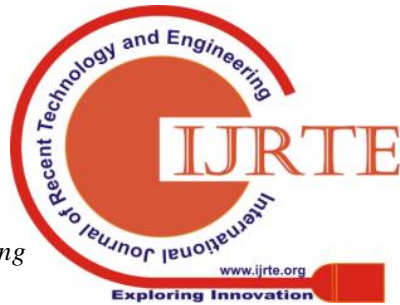




\section{Pso Research On Cutting Parameters In Awjm Process For Aluminum 6061 Alloy}

The work piece materials chosen for this study is Aluminium 6061 Alloys plate of $150 \mathrm{~mm}$ x $50 \mathrm{~mm}$ x $50 \mathrm{~mm}$ dimensions size has been used for performing the experiments.

\section{Response Surface Methodology}

RSM is a collection of mathematical and statistical techniques that are useful to find the correlation between the response and the variables. The work which initially generated interest in the package of techniques was a paper by Box and Wilson, Iqbal and Khan have been involved in developing prediction models using this renowned RSM for their advanced machining studies. This method is now broadly used in many fields, such as chemistry, biology and manufacturing. In the present study five process parameters are chosen and varied in three levels as shown in Table 1.

Table 1: Levels of Parameters Used in Experiment

\begin{tabular}{|l|c|c|c|c|c|}
\hline \multicolumn{1}{|c|}{ Levels } & $\begin{array}{c}\text { Water Pressure } \\
(\mathbf{P}) \mathbf{B a r}\end{array}$ & $\begin{array}{c}\text { Abrasive Flow Rate } \\
\left(\mathbf{m}_{\mathbf{f}}\right) \mathbf{K g} \mathbf{~ m}^{\mathbf{3}}\end{array}$ & $\begin{array}{c}\text { Orifice Diameter } \\
\left(\mathbf{d}_{\mathbf{0}}\right) \mathbf{~ m m}\end{array}$ & $\begin{array}{c}\text { Focusing Nozzle } \\
\text { Diameter }\left(\mathbf{d}_{\mathbf{f}}\right) \mathbf{m m}\end{array}$ & $\begin{array}{c}\text { Stand Off } \\
\text { Distance }(\mathbf{s}) \mathbf{m m}\end{array}$ \\
\hline Low & 3400 & 0.4 & 0.3 & 0.9 & 1 \\
\hline Intermediate & 3600 & 0.55 & 0.33 & 0.99 & 2 \\
\hline High & 3800 & 0.7 & 0.35 & 1.05 & 3 \\
\hline
\end{tabular}

Based on response surface methodology, Box-

Behnken design 46 sets of experimental design was selected. The parameters and its levels were selected based on the review of certain journals that have been acknowledged on AWJC on materials like 6063-T6 aluminum alloy [9], Metallic coated sheet steels [10] Metal Matrix Composites [11] and Ceramics [12].

\section{DATA COLLECTION AND EXPERIMENTATION}

The machine used to cut the American element Aluminium 6061 alloy was the AWJC machine is set with KMT ultrahigh pressure pump with the designed pressure of 4000bar, gravity feed type of abrasive hopper, an abrasive feeder system, a pneumatically controlled valve and a work piece table. The controller fixed in the control stand is used to adjust the SOD for different experiments. The abrasive water jet machine is programmed using numerical control code is to change the transverse speed and manage the supplement of abrasives. After the water is pumped at very high pressures resulting in high velocity of water jet of 1000 $\mathrm{m} / \mathrm{s}$ as it comes out of focusing nozzle cuts the materials of the desired size and shape. The KMT abrasive water jet cutting machine with its mixing chamber is shown in Figure 1.

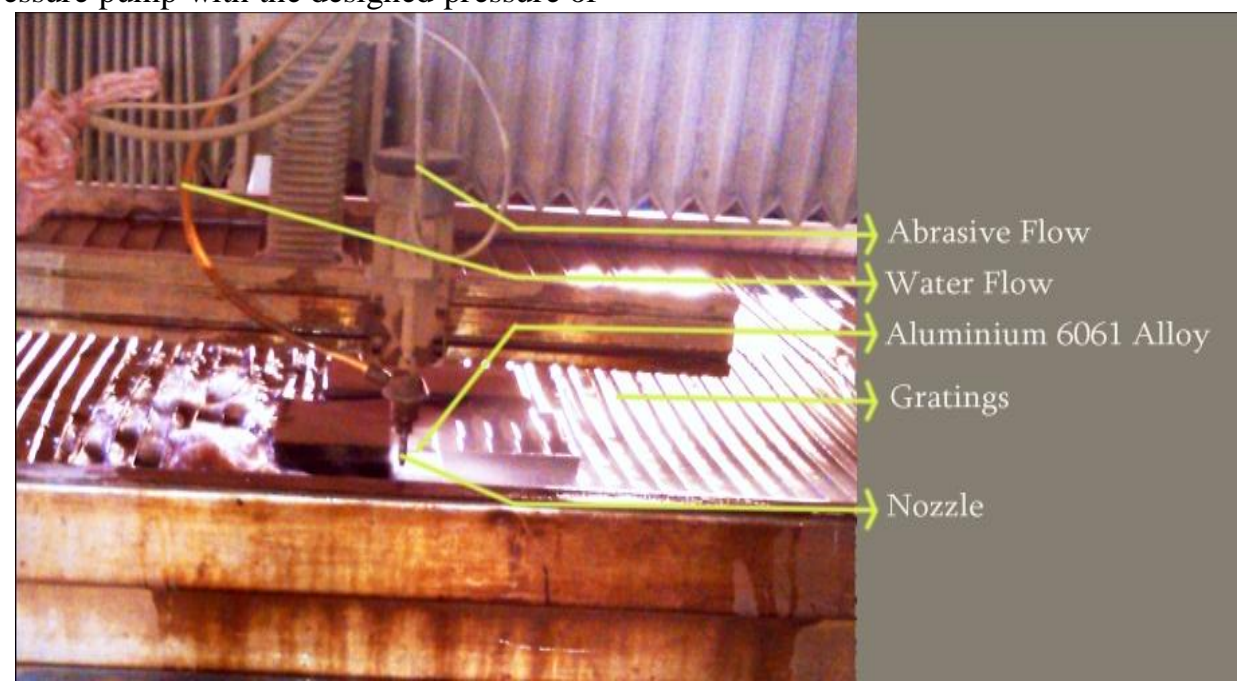

Figure 1: Experimental Setup of AWJM

For performing the experiments we have to design the combination of input parameters for each experiment and how many experiments has to be done. For this purpose using Minitab software according to the Box-Behnken design of Response surface methodology design of experiments, with five input parameters, 46 experimental design is selected and performed experimentally and machining time is observed for all experiments as shown in Table 2. The MRR is calculated by the formula;

$$
\operatorname{MRR}=\left(\mathrm{m}_{\mathrm{f}}-\mathrm{m}_{\mathrm{i}}\right) / \mathrm{t}
$$

Where, $\mathrm{m}_{\mathrm{f}}=$ mass of the material after machining, $\mathrm{m}_{\mathrm{i}}=$ mass of the material before machining and $t=$ Machining Time. The surface roughness for the machined Aluminium 6061 alloy is measured using Portable surface roughness tester in National College of Engineering, Tamilnadu, India.

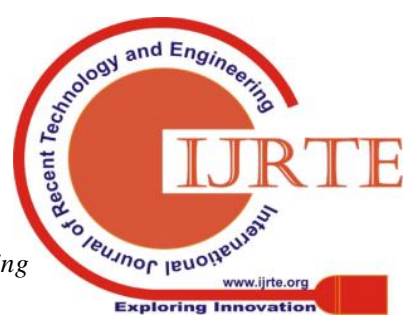


International Journal of Recent Technology and Engineering (IJRTE) ISSN: 2277-3878, Volume-8, Issue-2S3, July 2019

Table 2: Scheduling Matrix of the Experiments with the Optimal Model Data

\begin{tabular}{|c|c|c|c|c|c|c|c|}
\hline $\begin{array}{l}\text { Sl. } \\
\text { No }\end{array}$ & $\begin{array}{l}\text { Pressure } \\
\text { (Bar) }\end{array}$ & $\begin{array}{c}\text { Abrasive Flow } \\
\text { Rate } \\
\text { (Kg/min) }\end{array}$ & $\begin{array}{l}\text { Orifice Diameter } \\
(\mathbf{m m})\end{array}$ & $\begin{array}{c}\text { Focusing Tube } \\
\text { Diameter } \\
(\mathbf{m m})\end{array}$ & $\begin{array}{l}\text { Stand Off } \\
\text { Distance } \\
(\mathbf{m m})\end{array}$ & $\begin{array}{c}\text { MRR } \\
\mathrm{mm}^{3} / \mathrm{min}\end{array}$ & $\begin{array}{c}\text { SR } \\
(\mu \mathrm{m})\end{array}$ \\
\hline 1. & 3400 & 0.55 & 0.33 & 0.99 & 3 & 48.6111 & 3.57 \\
\hline 2. & 3600 & 0.55 & 0.33 & 0.9 & 1 & 53.6399 & 2.08 \\
\hline 3. & 3600 & 0.55 & 0.3 & 1.05 & 2 & 51.8519 & 2.21 \\
\hline 4. & 3600 & 0.55 & 0.33 & 0.9 & 3 & 50.8352 & 2.55 \\
\hline 5. & 3800 & 0.55 & 0.33 & 0.9 & 2 & 62.2222 & 1.90 \\
\hline 6. & 3600 & 0.55 & 0.33 & 0.99 & 2 & 51.8519 & 2.19 \\
\hline 7. & 3400 & 0.4 & 0.33 & 0.99 & 2 & 45.7516 & 3.20 \\
\hline 8. & 3600 & 0.7 & 0.35 & 0.99 & 2 & 53.6399 & 1.80 \\
\hline 9. & 3800 & 0.55 & 0.33 & 0.99 & 3 & 61.2423 & 2.07 \\
\hline 10. & 3800 & 0.55 & 0.3 & 0.99 & 2 & 62.2222 & 2.05 \\
\hline 11. & 3600 & 0.55 & 0.33 & 0.99 & 3 & 51.1696 & 2.54 \\
\hline 12. & 3400 & 0.55 & 0.33 & 1.05 & 2 & 47.7164 & 3.08 \\
\hline 13. & 3600 & 0.4 & 0.33 & 0.99 & 1 & 50.1792 & 1.99 \\
\hline 14. & 3600 & 0.55 & 0.33 & 0.99 & 2 & 52.9101 & 2.17 \\
\hline 15. & 3600 & 0.55 & 0.35 & 0.9 & 2 & 54.3901 & 2.08 \\
\hline 16. & 3600 & 0.55 & 0.3 & 0.9 & 2 & 51.8519 & 2.79 \\
\hline 17. & 3400 & 0.55 & 0.33 & 0.9 & 2 & 48.6111 & 3.30 \\
\hline 18. & 3600 & 0.55 & 0.33 & 0.99 & 2 & 52.9101 & 2.19 \\
\hline 19. & 3600 & 0.4 & 0.3 & 0.99 & 2 & 47.7164 & 2.36 \\
\hline 20. & 3400 & 0.55 & 0.35 & 0.99 & 2 & 48.3092 & 2.95 \\
\hline 21. & 3800 & 0.4 & 0.33 & 0.99 & 2 & 58.4785 & 1.89 \\
\hline 22. & 3600 & 0.7 & 0.33 & 0.99 & 3 & 54.7731 & 2.25 \\
\hline 23. & 3600 & 0.7 & 0.33 & 0.99 & 1 & 56.3607 & 1.68 \\
\hline 24. & 3600 & 0.4 & 0.35 & 0.99 & 2 & 49.2264 & 2.29 \\
\hline 25. & 3600 & 0.4 & 0.33 & 0.9 & 2 & 48.9168 & 2.36 \\
\hline 26. & 3600 & 0.55 & 0.35 & 0.99 & 3 & 51.1696 & 2.50 \\
\hline 27. & 3600 & 0.7 & 0.33 & 0.9 & 2 & 55.9552 & 2.14 \\
\hline 28. & 3400 & 0.55 & 0.33 & 0.99 & 1 & 49.2264 & 2.65 \\
\hline 29. & 3600 & 0.7 & 0.3 & 0.99 & 2 & 56.7721 & 2.18 \\
\hline 30. & 3600 & 0.55 & 0.33 & 1.05 & 1 & 50.8352 & 1.90 \\
\hline 31. & 3600 & 0.55 & 0.3 & 0.99 & 1 & 51.8519 & 1.99 \\
\hline 32. & 3800 & 0.7 & 0.33 & 0.99 & 2 & 64.8148 & 1.70 \\
\hline 33. & 3600 & 0.4 & 0.33 & 1.05 & 2 & 48.6111 & 2.40 \\
\hline 34. & 3600 & 0.55 & 0.3 & 0.99 & 3 & 52.1999 & 2.68 \\
\hline 35. & 3600 & 0.55 & 0.33 & 0.99 & 2 & 52.9101 & 2.20 \\
\hline 36. & 3800 & 0.55 & 0.33 & 1.05 & 2 & 59.8291 & 1.99 \\
\hline 37. & 3400 & 0.7 & 0.33 & 0.99 & 2 & 51.8519 & 2.80 \\
\hline 38. & 3600 & 0.55 & 0.35 & 1.05 & 2 & 51.1696 & 2.34 \\
\hline 39. & 3400 & 0.55 & 0.3 & 0.99 & 2 & 48.9168 & 3.23 \\
\hline 40. & 3600 & 0.4 & 0.33 & 0.99 & 3 & 48.3092 & 2.69 \\
\hline 41. & 3600 & 0.55 & 0.33 & 0.99 & 2 & 53.2725 & 2.18 \\
\hline 42. & 3600 & 0.55 & 0.35 & 0.99 & 1 & 52.5526 & 1.80 \\
\hline 43. & 3800 & 0.55 & 0.35 & 0.99 & 2 & 59.3724 & 1.82 \\
\hline 44. & 3600 & 0.7 & 0.33 & 1.05 & 2 & 56.7721 & 2.03 \\
\hline 45. & 3600 & 0.55 & 0.33 & 1.05 & 3 & 51.1696 & 2.73 \\
\hline 46. & 3800 & 0.55 & 0.33 & 0.99 & 1 & 61.2423 & 1.72 \\
\hline
\end{tabular}

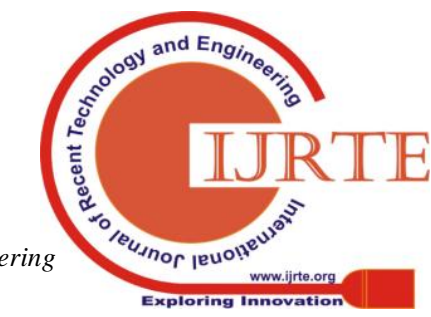


The mathematical model for the experimental data by cutting the Aluminium 6061 alloy using abrasive water jet machine for MRR and SR is developed using linear regression analysis through Minitab software. The developed regression equations are given below.

Material Removal Rate $=195.719-0.360226 \mathrm{~A}+$ $99.1877 \mathrm{~B}+1516.21 \mathrm{C}+364.430 \mathrm{D}-6.05121 \mathrm{E}+$ 6.23441E-05 A*A - $1.34839 \mathrm{~B} * \mathrm{~B}-802.864 \mathrm{C} * \mathrm{C}-82.6080$ $\mathrm{D} * \mathrm{D}-0.410467 \mathrm{E} * \mathrm{E}+0.00196733 \mathrm{~A} * \mathrm{~B}-0.102446 \mathrm{~A} * \mathrm{C}-$ $0.0265738 \mathrm{~A} * \mathrm{D}+0.000769113 \mathrm{~A} * \mathrm{E}-300.422 \mathrm{~B} * \mathrm{C}+$ 15.6465 B*D + 0.470717 B*E - 438.266 C*D - 18.4785 $\mathrm{C} * \mathrm{E}+10.3697 \mathrm{D} * \mathrm{E}$

Surface Roughness $=179.473-0.0589755 \mathrm{~A}+6.28678 \mathrm{~B}$ - 132.385 C - 94.7475 D + 1.76521 E + 7.04007E-06 A*A $2.89173 \mathrm{~B} * \mathrm{~B}+32.5335 \mathrm{C}^{*} \mathrm{C}+19.3324 \mathrm{D} * \mathrm{D}+0.0255693$ $\mathrm{E} * \mathrm{E}+0.00175000 \mathrm{~A} * \mathrm{~B}+0.00161011 \mathrm{~A} * \mathrm{C}+0.00528029$ $\mathrm{A} * \mathrm{D}-7.12500 \mathrm{E}-04 \mathrm{~A} * \mathrm{E}-19.9095 \mathrm{~B} * \mathrm{C}-3.55958 \mathrm{~B} * \mathrm{D}-$ $0.216667 \mathrm{~B} * \mathrm{E}+113.234 \mathrm{C} * \mathrm{D}-0.0302120 \mathrm{C} * \mathrm{E}+1.16942$ $\mathrm{D} * \mathrm{E}$

\section{OPTIMIZATION OF MRR AND SR BY PARTICLE SWARM OPTIMIZATION \& RESULTS}

PSO is the most advanced evolutionary computational intelligence based optimization techniques for optimizing real world multimodal problems.

PSO, a known advanced method that was build up by Kennedy and Eberhart.

It shows general evolutionary computation characteristics together with the initialization of population with arbitrary solution and finding the optima by filling in the generations. Potential energy solutions are known as particles.

They are subsequently "flown" via the critical gap followed by the present optimum particles.

Every particle keeping the follow with the coordinates in the critical space achieved an excellence solution.

This significance is known as 'pBest'. One more excellent value which is followed by the global version of the PSO is taken as a whole best value and its location received till that instant by means of any of the particle in the population. This location is known as "gBest".

The PSO idea contains, every step, varying the velocity (i.e. accelerating) of every particle towards its both the pBest and gBest locations.

Random term weighs acceleration with individual arbitrary numbers are being produced for acceleration towards both the pBest and gBest locations.

Updating the particles are established by adopting the below equations.

$$
\begin{gathered}
\mathrm{V}_{\mathrm{i}+1}=\mathrm{w}^{*} \mathrm{~V}_{\mathrm{i}}+\mathrm{c}_{1} * \mathrm{r}_{1} *\left(\mathrm{pBest}_{\mathrm{i}}-\mathrm{X}_{\mathrm{i}}\right)+\mathrm{c}_{2} * \mathrm{r}_{2} *\left(\text { gBesti- } \mathrm{X}_{\mathrm{i}}\right) \\
\mathrm{X}_{\mathrm{i}+1}=\mathrm{X}_{\mathrm{i}}+\mathrm{V}_{\mathrm{i}+1}
\end{gathered}
$$

Equation (1) gives a original velocity $\left(\mathrm{V}_{\mathrm{i}+1}\right)$ for all particles depending on the preceding velocity, along with pBest and gBest. Equation (2) gives the update individual particles location $\left(\mathrm{X}_{\mathrm{i}}\right)$ in solution hyperspace.

The numbers that are in random $r_{1}$ and $r_{2}$ in Equation (1) are independently produced in the range $(0,1)$. During AWJM, Material Removal Rate and Surface Roughness achieved by the process is the main concern of the engineers.
To cut a particular thickness of material, optimum setting of control parameters such as water pressure, abrasive flow rate, orifice diameter, focusing nozzle diameter and stand off distance is very necessary.

In this Particle Swarm Optimization process, the Mathematical Modeling equation is considered as objective functions for MRR and SR.

The Table 3 shows the comparison between the Predicted Values of MRR and SR with the actual values and their corresponding error values is also shown in the same table.

The Comparison between Predicted and actual values of MRR and SR using PSO is depicted in Figure 2 and 3 and the predicted values are found very closer to the experimental values.

The Figure 4 and 5 shows the bar chart for RSM and PSO Error values for Material removal rate and Surface roughness for Aluminium 6061 Alloy by cutting through Abrasive water jet machining process which shows that the error values for PSO is very lower than that of RSM.

Table 4 shows the comparison of RSM and PSO Least Mean Square Error Values for MRR and SR which shows that the Least Mean Square Error for PSO is very less while compared to RSM.

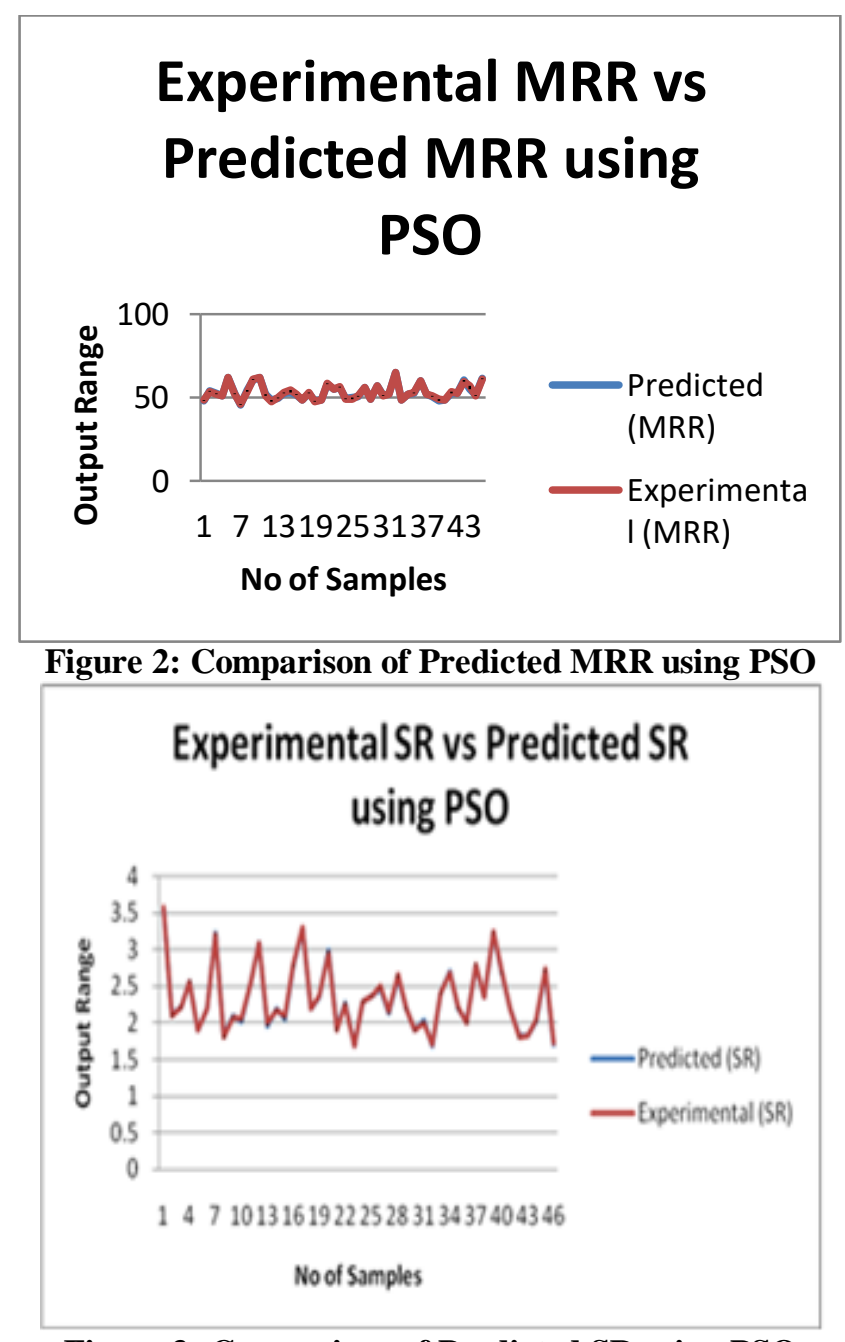

Figure 3: Comparison of Predicted SR using PSO

Published By: 
Table 3: Comparison between the Experimental and Predicted Values Using PSO

\begin{tabular}{|c|c|c|c|c|c|c|}
\hline Sl. No. & Experimental MRR & Predicted MRR & Experimental SR & Predicted SR & Error MRR & Error SR \\
\hline 1. & 48.6111 & 47.9094 & 3.57 & 3.5643 & 1.44349747 & 0.159664 \\
\hline 2. & 53.6399 & 53.9668 & 2.08 & 2.1158 & 0.60943439 & 1.721154 \\
\hline 3. & 51.8519 & 52.4292 & 2.21 & 2.2185 & 1.11336325 & 0.384615 \\
\hline 4. & 50.8352 & 51.1057 & 2.55 & 2.5675 & 0.53211161 & 0.686275 \\
\hline 5. & 62.2222 & 62.1502 & 1.90 & 1.9045 & 0.11571433 & 0.236842 \\
\hline 6. & 51.8519 & 52.7085 & 2.19 & 2.1854 & 1.65201275 & 0.210046 \\
\hline 7. & 45.7516 & 45.6877 & 3.20 & 3.2208 & 0.13966725 & 0.65 \\
\hline 8. & 53.6399 & 54.3964 & 1.80 & 1.8249 & 1.41033074 & 1.383333 \\
\hline 9. & 61.2423 & 60.6796 & 2.07 & 2.0830 & 0.91880939 & 0.628019 \\
\hline 10. & 62.2222 & 61.8824 & 2.05 & 2.0093 & 0.54610734 & 1.985366 \\
\hline 11. & 51.1696 & 51.8007 & 2.54 & 2.5421 & 1.23334949 & 0.082677 \\
\hline 12. & 47.7164 & 48.3875 & 3.08 & 3.0887 & 1.40643468 & 0.282468 \\
\hline 13. & 50.1792 & 49.5237 & 1.99 & 1.9506 & 1.30631816 & 1.979899 \\
\hline 14. & 52.9101 & 52.7085 & 2.17 & 2.1854 & 0.38102366 & 0.709677 \\
\hline 15. & 54.3901 & 53.0433 & 2.08 & 2.0448 & 2.47618592 & 1.692308 \\
\hline 16. & 51.8519 & 51.5976 & 2.79 & 2.7719 & 0.49043526 & 0.648746 \\
\hline 17. & 48.6111 & 48.7309 & 3.3 & 3.2909 & 0.24644577 & 0.275758 \\
\hline 18. & 52.9101 & 52.7085 & 2.19 & 2.1854 & 0.38102366 & 0.210046 \\
\hline 19. & 47.7164 & 47.8485 & 2.36 & 2.3490 & 0.27684402 & 0.466102 \\
\hline 20. & 48.3092 & 48.6884 & 2.95 & 2.9912 & 0.78494365 & 1.39661 \\
\hline 21. & 58.4785 & 58.0323 & 1.89 & 1.9196 & 0.76301547 & 1.566138 \\
\hline 22. & 54.7731 & 55.1529 & 2.25 & 2.2763 & 0.69340607 & 1.168889 \\
\hline 23. & 56.3607 & 56.0062 & 1.68 & 1.6791 & 0.62898438 & 0.053571 \\
\hline 24. & 49.2264 & 49.5752 & 2.29 & 2.2808 & 0.70856288 & 0.401747 \\
\hline 25. & 48.9168 & 49.8158 & 2.36 & 2.3712 & 1.83781441 & 0.474576 \\
\hline 26. & 51.1696 & 50.7388 & 2.50 & 2.4740 & 0.84190613 & 1.04 \\
\hline 27. & 55.9552 & 56.0170 & 2.14 & 2.1308 & 0.1104455 & 0.429907 \\
\hline 28. & 49.2264 & 49.2116 & 2.65 & 2.6171 & 0.03006517 & 1.241509 \\
\hline 29. & 56.7721 & 57.1761 & 2.18 & 2.1918 & 0.71161715 & 0.541284 \\
\hline 30. & 50.8352 & 51.2708 & 1.90 & 1.8966 & 0.85688657 & 0.178947 \\
\hline 31. & 51.8519 & 52.0751 & 1.99 & 2.0290 & 0.43045674 & 1.959799 \\
\hline 32. & 64.8148 & 64.7741 & 1.70 & 1.6881 & 0.0627943 & 0.7 \\
\hline 33. & 48.6111 & 48.3231 & 2.40 & 2.4075 & 0.59245728 & 0.3125 \\
\hline 34. & 52.1999 & 52.1892 & 2.68 & 2.6930 & 0.02049812 & 0.485075 \\
\hline 35. & 52.9101 & 52.7085 & 2.20 & 2.1854 & 0.38102366 & 0.663636 \\
\hline 36. & 59.8291 & 60.2123 & 1.99 & 2.0191 & 0.640491 & 1.462312 \\
\hline 37. & 51.8519 & 52.1934 & 2.80 & 2.7794 & 0.65860653 & 0.735714 \\
\hline 38. & 51.1696 & 50.5879 & 2.34 & 2.3407 & 1.13680779 & 0.029915 \\
\hline 39. & 48.9168 & 48.1904 & 3.23 & 3.2249 & 1.4849704 & 0.157895 \\
\hline 40. & 48.3092 & 48.3879 & 2.69 & 2.6777 & 0.16290893 & 0.457249 \\
\hline 41. & 53.2725 & 52.7085 & 2.18 & 2.1854 & 1.05870759 & 0.247706 \\
\hline 42. & 52.5526 & 52.4725 & 1.80 & 1.8130 & 0.15241872 & 0.722222 \\
\hline 43. & 59.3724 & 60.3314 & 1.82 & 1.8078 & 1.61522862 & 0.67033 \\
\hline 44. & 56.7721 & 55.2285 & 2.03 & 2.0070 & 2.71894117 & 1.133005 \\
\hline 45. & 51.1696 & 51.5206 & 2.73 & 2.6991 & 0.68595416 & 1.131868 \\
\hline 46. & 61.2423 & 61.3665 & 1.72 & 1.7059 & 0.20280101 & 0.819767 \\
\hline
\end{tabular}


Pso Research On Cutting Parameters In Awjm Process For Aluminum 6061 Alloy

Table 4: Comparison of RSM and PSO Least Mean Square Error for MRR and SR

\begin{tabular}{|c|c|c|c|c|c|c|c|c|}
\hline $\begin{array}{l}\text { Sl. } \\
\text { No. }\end{array}$ & $\begin{array}{l}\text { Error MRR } \\
\text { Using RSM }\end{array}$ & $\begin{array}{c}\text { Error MRR } \\
\text { using PSO }\end{array}$ & $\begin{array}{c}\text { Least Mean } \\
\text { Square Error } \\
\text { MRR Using } \\
\text { RSM }\end{array}$ & $\begin{array}{c}\text { Least Mean } \\
\text { Square Error } \\
\text { MRR Using } \\
\text { PSO }\end{array}$ & $\begin{array}{c}\text { Error SR } \\
\text { Using RSM }\end{array}$ & $\begin{array}{c}\text { Error SR } \\
\text { Using PSO }\end{array}$ & $\begin{array}{c}\text { Least Mean } \\
\text { Square Error } \\
\text { SR Using RSM }\end{array}$ & $\begin{array}{c}\text { Least Mean } \\
\text { Square Error } \\
\text { SR Using PSO }\end{array}$ \\
\hline 1. & 1.443585 & 1.443497 & \multirow{46}{*}{0.148249} & \multirow{46}{*}{0.12614} & 0.15964 & 0.159664 & \multirow{46}{*}{0.137694} & \multirow{46}{*}{0.137647} \\
\hline 2. & 0.609506 & 0.609434 & & & 1.72271 & 1.721154 & & \\
\hline 3. & 1.113345 & 1.113363 & & & 0.38539 & 0.384615 & & \\
\hline 4. & 0.53218 & 0.532112 & & & 0.68585 & 0.686275 & & \\
\hline 5. & 0.11579 & 0.115714 & & & 0.23761 & 0.236842 & & \\
\hline 6. & 1.651953 & 1.652013 & & & 0.20923 & 0.210046 & & \\
\hline 7. & 0.139565 & 0.139667 & & & 0.65087 & 0.65 & & \\
\hline 8. & 1.410356 & 1.410331 & & & 1.38293 & 1.383333 & & \\
\hline 9. & 0.918782 & 0.918809 & & & 0.62955 & 0.628019 & & \\
\hline 10. & 0.546128 & 0.546107 & & & 1.98682 & 1.985366 & & \\
\hline 11. & 1.233395 & 1.233349 & & & 0.08124 & 0.082677 & & \\
\hline 12. & 1.4064 & 1.406435 & & & 0.28142 & 0.282468 & & \\
\hline 13. & 1.306339 & 1.306318 & & & 1.98073 & 1.979899 & & \\
\hline 14. & 0.381082 & 0.381024 & & & 0.7105 & 0.709677 & & \\
\hline 15. & 2.476147 & 0.476186 & & & 1.69355 & 1.692308 & & \\
\hline 16. & 0.490423 & 0.490435 & & & 0.64989 & 0.648746 & & \\
\hline 17. & 0.246409 & 0.246446 & & & 0.27654 & 0.275758 & & \\
\hline 18. & 0.381082 & 0.381024 & & & 0.20923 & 0.210046 & & \\
\hline 19. & 0.276932 & 0.276844 & & & 0.46431 & 0.466102 & & \\
\hline 20. & 0.784941 & 0.784944 & & & 1.39724 & 1.39661 & & \\
\hline 21. & 0.762979 & 0.763015 & & & 1.56395 & 1.566138 & & \\
\hline 22. & 0.693319 & 0.693406 & & & 1.16724 & 1.168889 & & \\
\hline 23. & 0.628993 & 0.628984 & & & 0.05293 & 0.053571 & & \\
\hline 24. & 0.708614 & 0.708563 & & & 0.40076 & 0.401747 & & \\
\hline 25. & 1.837778 & 1.837814 & & & 0.47499 & 0.474576 & & \\
\hline 26. & 0.841824 & 0.841906 & & & 1.04148 & 1.04 & & \\
\hline 27. & 0.11053 & 0.110446 & & & 0.42778 & 0.429907 & & \\
\hline 28. & 0.030145 & 0.030065 & & & 1.23968 & 1.241509 & & \\
\hline 29. & 0.711547 & 0.711617 & & & 0.53922 & 0.541284 & & \\
\hline 30. & 0.856829 & 0.856887 & & & 0.17781 & 0.178947 & & \\
\hline 31. & 0.430451 & 0.430457 & & & 1.96228 & 1.959799 & & \\
\hline 32. & 0.062823 & 0.062794 & & & 0.70083 & 0.7 & & \\
\hline 33. & 0.592409 & 0.592457 & & & 0.3126 & 0.3125 & & \\
\hline 34. & 0.020404 & 0.020498 & & & 0.48561 & 0.485075 & & \\
\hline 35. & 0.381082 & 0.381024 & & & 0.66282 & 0.663636 & & \\
\hline 36. & 0.640535 & 0.640491 & & & 1.4636 & 1.462312 & & \\
\hline 37. & 0.65866 & 0.658607 & & & 0.73733 & 0.735714 & & \\
\hline 38. & 1.136787 & 1.136808 & & & 0.02899 & 0.029915 & & \\
\hline 39. & 1.484928 & 1.48497 & & & 0.15912 & 0.157895 & & \\
\hline 40. & 0.162944 & 0.162909 & & & 0.45591 & 0.457249 & & \\
\hline 41. & 1.058765 & 1.058708 & & & 0.24853 & 0.247706 & & \\
\hline 42. & 0.152343 & 0.152419 & & & 0.72328 & 0.722222 & & \\
\hline 43. & 1.615305 & 1.615229 & & & 0.66866 & 0.67033 & & \\
\hline 44. & 2.718975 & 0.1894117 & & & 1.13511 & 1.133005 & & \\
\hline 45. & 0.685909 & 0.685954 & & & 1.1317 & 1.131868 & & \\
\hline 46. & 0.202849 & 0.202801 & & & 0.82097 & 0.819767 & & \\
\hline
\end{tabular}




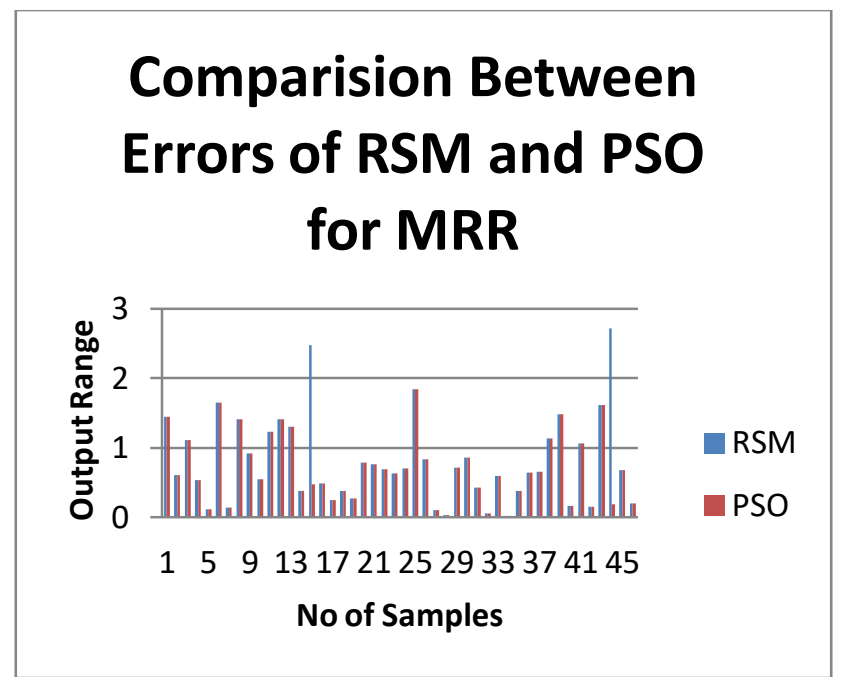

Figure 4: Bar Chart on RSM and PSO Error Values for MRR

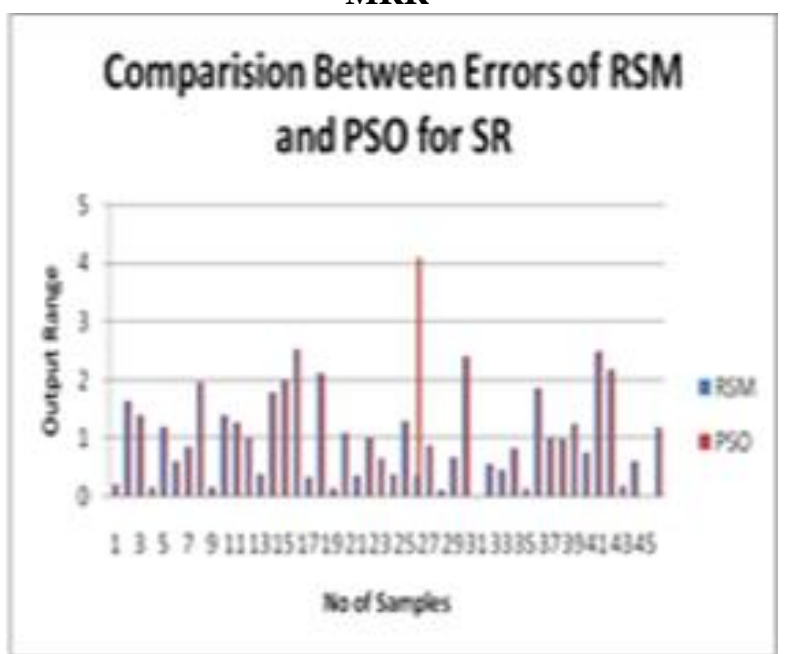

Figure 5: Bar Chart on RSM and PSO Error Values for SR

Figure 6 and 7 shows the marching steps for maximum material removal rate and minimum surface roughness and found that the optimized value of MRR and SR using Single Objective Particle Swarm Optimization is shown in Table 5. The results of the PSO using Matlab are shown in Figure 8 for MRR and Figure 9 for SR.

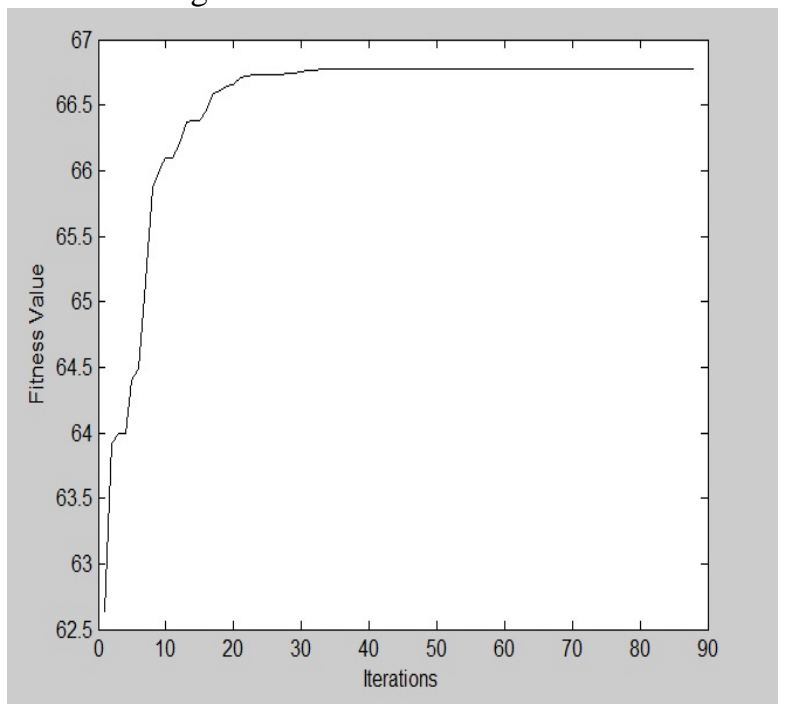

Figure 6: Marching Steps for Maximum MMR

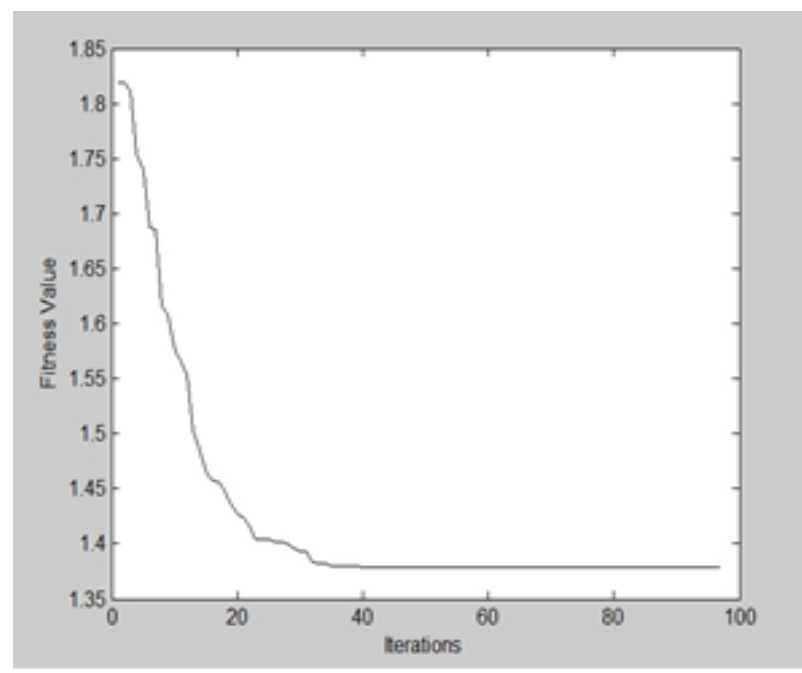

Figure7: Marching Steps for Minimum SR

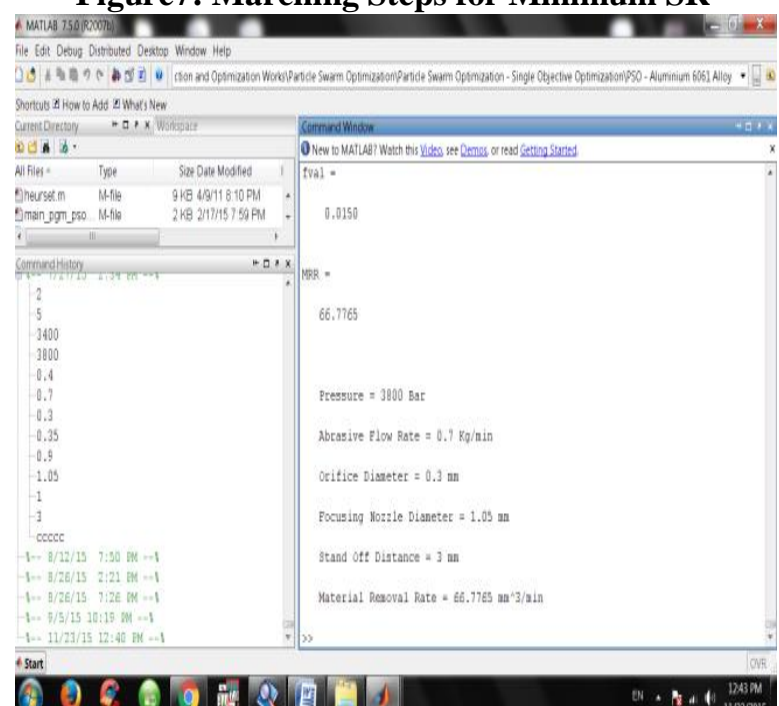

Figure 8: Optimal Solution of PSO for MRR Figure

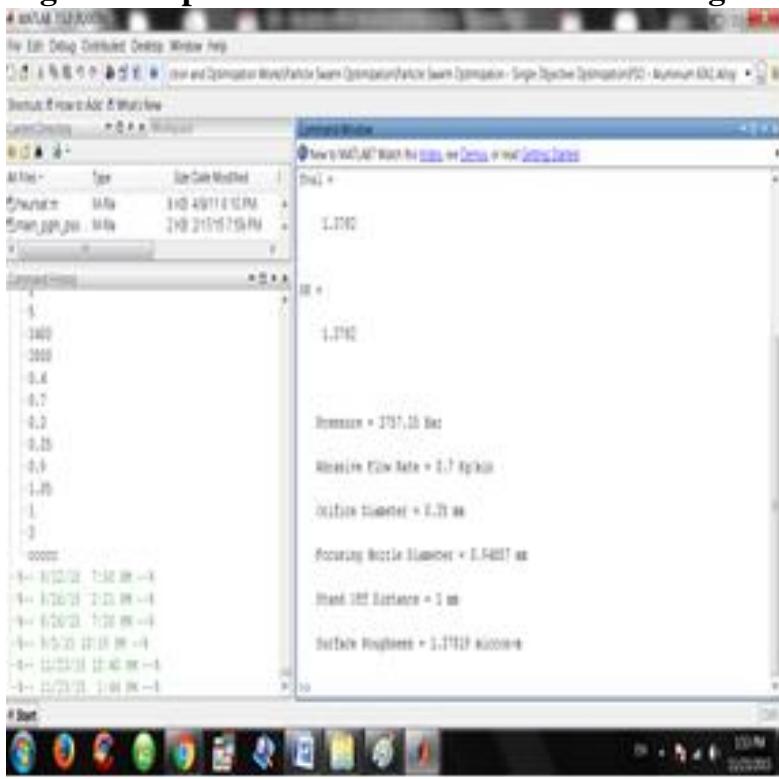

9: Optimal Solution of PSO for SR

Published By: 
Table 5: Optimized Value of MRR and SR using Particle Swarm Optimization

\begin{tabular}{|c|c|c|c|c|c|c|c|}
\hline $\begin{array}{l}\text { Sl } \\
\dot{\mathrm{N}} \\
\mathbf{0}\end{array}$ & $\begin{array}{c}\text { Press } \\
\text { ure } \\
\text { Bar }\end{array}$ & $\begin{array}{c}\text { Abra } \\
\text { sive } \\
\text { Flow } \\
\text { Rate } \\
\text { Kg/m } \\
\text { in }\end{array}$ & $\begin{array}{c}\text { Orific } \\
\text { e } \\
\text { Diam } \\
\text { eter } \\
\text { mm }\end{array}$ & $\begin{array}{c}\text { Focus } \\
\text { ing } \\
\text { Nozzl } \\
\text { e } \\
\text { Diam } \\
\text { eter } \\
\text { mm }\end{array}$ & $\begin{array}{c}\text { Stan } \\
\text { d Off } \\
\text { Dista } \\
\text { nce } \\
\text { mm }\end{array}$ & $\begin{array}{c}\text { Mate } \\
\text { rial } \\
\text { Remo } \\
\text { val } \\
\text { Rate } \\
\text { mm }^{3} / \\
\text { min }\end{array}$ & $\begin{array}{c}\text { Surfac } \\
\text { e } \\
\text { Rough } \\
\text { ness } \\
\mu \mathrm{m}\end{array}$ \\
\hline 1. & 3800 & 0.7 & 0.3 & 1.05 & 3 & $\begin{array}{l}66.77 \\
65\end{array}$ & ---- \\
\hline 2. & $\begin{array}{c}3757 . \\
15\end{array}$ & 0.7 & 0.35 & $\begin{array}{c}0.946 \\
57\end{array}$ & 1 & ---- & $\begin{array}{c}1.3781 \\
9\end{array}$ \\
\hline
\end{tabular}

\section{CONCLUSION}

In this paper, using linear regression analysis a mathematical model is developed for Aluminium 6061 Alloy through Abrasive water jet machining process by Minitab software is done. Then the prediction of MRR and SR for Aluminium 6061 Alloy by cutting through AWJM process by the tool named PSO is done which illustrates that the experimental values are closer to the predicted values. The error comparison between RSM and PSO is also studied which shows the least MSE is very less in PSO while compared with RSM. Also the prediction and optimization of MRR and SR on Aluminium 6061 alloy using single objective PSO is presented in this paper and found that the optimized value of MRR and SR is $66.7765 \mathrm{~mm}^{3} / \mathrm{min}$ and $1.37819 \mu \mathrm{m}$.

\section{REFERENCES}

1. Adel A. Abdel-Rahman., A Closed-Form Expression For An Abrasive Waterjet Cutting Model for Ceramic Materials. International Journal Of Mathematical Models and Methods in Applied Sciences, Volume 5, Issue 4, 2011, pp. 722-729.

2. C. Ma, R.T. Deam., A Correlation for Predicting the Kerf Profile From Abrasive Water Jet Cutting. Experimental Thermal and Fluid Science, Volume 30, 2006, pp. 337 343.

3. H. Liu, J. Wang, N. Kelson, R.J. Brown., Study of Abrasive Waterjet Characteristics by CFD Simulation, Journal of Materials Processing Technology, Volume 153-154, 2004, pp. 488-493.

4. M. Hashish, A Modeling Study of Metal Cutting with Abrasive Water jets, Transactions of ASME: Journal of Engineering Materials and Technology, Volume 106, Issue (1), (1984), pp. 88-100.

5. M. Hashish, A Model for Abrasive Water Jet (AWJ) Machining, Transactions of ASME: Journal of Engineering Materials and Technology, Volume 111, Issue (2), 1989, pp. 154-162.

6. S. Paul, A.M. Hoogstrate, C.A. Van Luttervelt, H.J.J. Kals, Analytical and Experimental Modeling of Abrasive Water Jet Cutting of Ductile Materials, Journal of Material Processing Technology, Volume 73, (1998), pp. 189-199.

7. S. Paul, A.M. Hoogstrate, C.A. Van Luttervelt, H.J.J. Kals, Analytical Modeling of the Total Depth of Cut in Abrasive Water Jet Machining of Polycrystalline Brittle Materials, Journal of Material Processing Technology, Volume 73, (1998), pp. 206-212.

8. G.S. Choi, G.H. Choi, Process Analysis and Monitoring in Abrasive Water Jet Machining of Alumina Ceramics, International Journal of Machine Tools and Manufacture, Volume 37, (1997) 295-307.
9. Farhad Kolahan,A. Hamid Khajavi., Statistical Approach for Predicting and Optimizing Depth of Cut in AWJ Machining for 6063-T6 Al Alloy, World Academy of Science, Engineering and Technology, Volume 59, (2009), pp. 142-145.

10. J. Wang, W. C. K. Wong., A Study of Abrasive Waterjet Cutting of Metallic Coated Sheet Steels, International Journal of Machine Tools \& Manufacture, Volume 39, 1999, pp. 855-870.

11. Wlodzimierz Wilk, M., Barbara Staniewicz-Brudnik, Abrasive Machining of Metal Matrix Composites. International Conference Advanced Manufacturing Operations, pp. 373-379.

12. Adel A. Abdel-Rahman., An Abrasive Waterjet Model for Cutting Ceramics, Mathematical Models for Engineering Science, ISBN: 978-960-474-252-3, pp. 6872. 